\title{
Editorial
}

Neuropsychobiology

\section{Do Immune Dysregulations and Oxidative Damage Drive Mood and Psychotic Disorders?}

\author{
Manuel Morrens ${ }^{\mathrm{a}, \mathrm{b}} \quad$ Violette Coppens $^{\mathrm{a}, \mathrm{b}} \quad$ Sebastian Walther ${ }^{\mathrm{c}}$ \\ ${ }^{a}$ Collaborative Antwerp Psychiatric Research Institute (CAPRI), Faculty of Medicine and Health Sciences, Campus

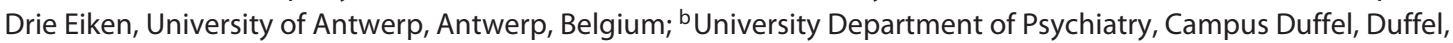 \\ Belgium; ' Translational Research Center, University Hospital of Psychiatry, University of Bern, Bern, Switzerland
}

Psychotic disorders such as schizophrenia and mood disorders including bipolar disorder (BD) and major depressive disorder (MDD) have overlapping clinical presentations and share similarities in several underlying endophenotypic abnormalities, such as cognitive and motor deficits $[1,2]$. These pathologies further share progressive neurobiological disturbances, including structural brain changes (e.g., prefrontal lobe volume reductions, enlarged lateral ventricles) [3] and abnormal functional connectivity $[4,5]$. It is hypothesized that these progressive changes are mediated by neuroinflammatory and oxidative stress (OS) [6] (Fig. 1).

\section{Immune Abnormalities in Mood and Psychotic Disorders}

Peripheral and central immune abnormalities are present in both mood and psychotic disorders [7-9]. Centrally, immune alterations are evidenced by abnormal microglial activation patterns $[10,11]$ as well as a disequilibrium in the kynurenine pathway [12]. Activated microglia have been associated with excessive synaptic pruning in schizophrenia [13], thus affecting brain structure and functioning. Moreover, the kynurenine path- way, which is activated by inflammatory cytokines, additionally accounts for altered brain operation in these illnesses. This pathway consists of two branches, with 3-OH-kynurenine and quinolinic acid being produced by microglia on the one hand and kynurenic acid by astrocytes on the other. Interestingly, the microglia-generated metabolites are known to be neurotoxic. Moreover, across psychotic disorders including schizophrenia, BD, and MDD, both quinolinic acid and kynurenic acid were shown to be dysregulated, affecting glutamatergic and cholinergic neurotransmission, which may bridge immune effects and mood- and psychosis-related symptoms. This is in line with the findings of Condray et al. [14] who demonstrated microglial kynurenine metabolites not only to correlate with symptom severity in neuroleptic-naive schizophrenia patients but also to predict clinical change at 4 weeks of treatment. Finally, a proinflammatory state has an impact on growth factor levels (such as brain-derived neurotrophic factor or vascular endothelial growth factor) in mood and psychotic disorders [9], generally influencing synaptic homeostasis and neuronal regeneration. In sum, central nervous immune dysregulation may critically affect symptoms of psychotic disorders.

\section{KARGER}

(c) 2019 S. Karger AG, Basel

karger@karger.com

www.karger.com/nps
Manuel Morrens

Faculty of Medicine and Health Sciences, University of Antwerp

Universiteitsplein 1

BE-2610 Antwerp (Belgium)

E-Mail manuel.morrens@uantwerpen.be 


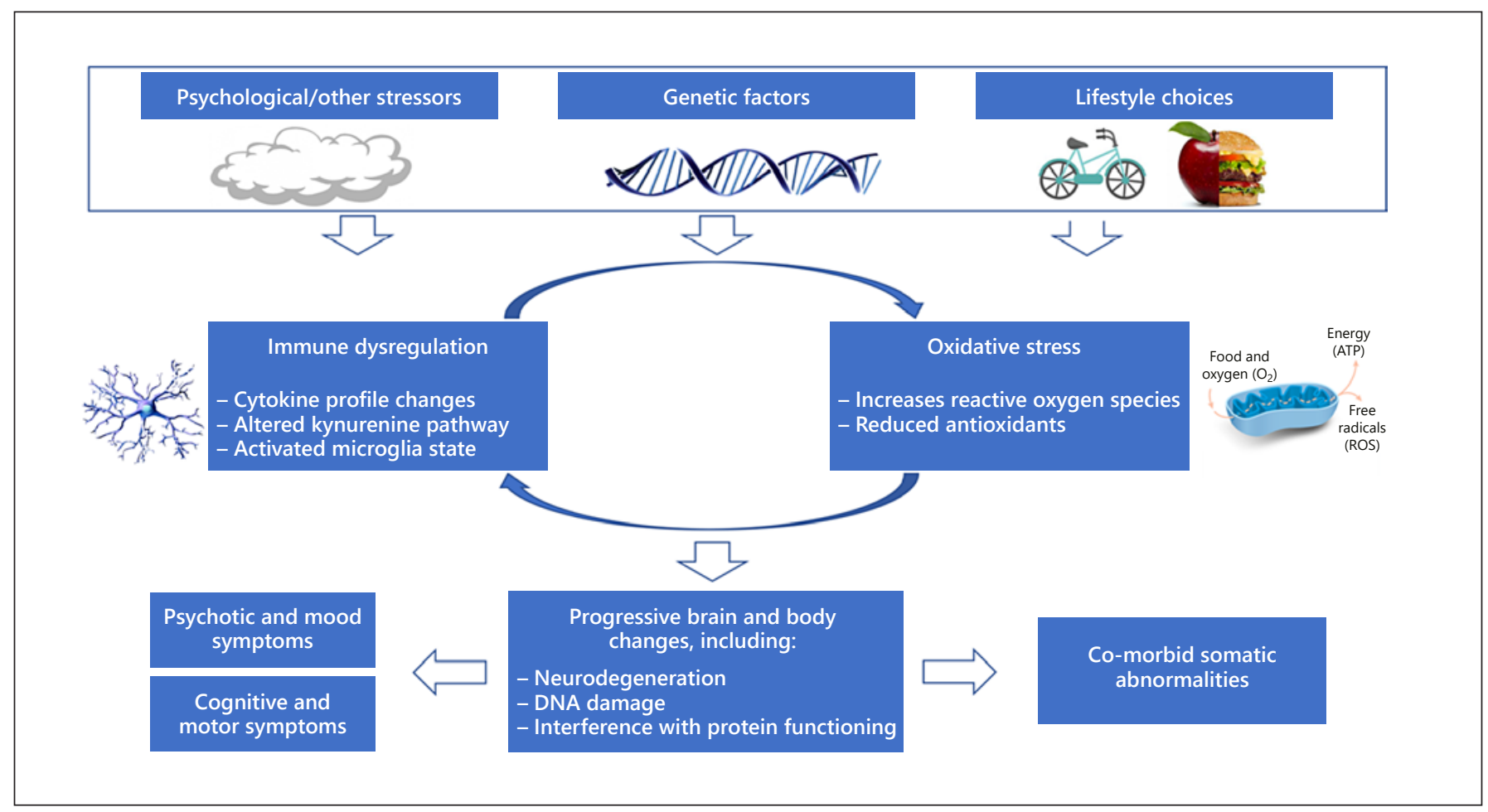

Fig. 1. A model for immune dysregulation and OS towards psychotic and mood symptoms.

Besides central immune abnormalities, peripheral proinflammatory cytokine alterations have been found in these three illnesses [15]. Moreover, these cytokine changes are comparably present in these disorders, again suggesting a common underlying pathway for immune dysfunction [15]. Interestingly, proinflammatory activity has been associated with structural brain changes [16] as well as with the cognitive and motor dysfunctions $[17,18]$ seen in each of these disorders. It should be noted that although peripheral and central immune alterations are present, these may be unrelated [19] and may even be inversely related $[20,21]$, which could point towards compensatory reverse mechanisms in the brain following systemic proinflammatory immune activity $[20,21]$. Nevertheless, methodological shortcomings limit this emerging research field; thus, caution is warranted in interpreting such findings. For example, microglial PET-tracer specificity is unclear, and different mathematical models calculating microglial activation in these PET studies have yielded different results. Nonetheless, results suggest peripheral systemic abnormal immune processes being present in mood and psychotic disorder, which may be independent from those present in the central nervous system.

\section{OS in Mood and Psychotic Disorders}

Chronic inflammation is bidirectionally associated to OS, also present in schizophrenia and mood disorders [22]. OS induces cell damage due to an imbalance in the release of toxic-free radicals (reactive oxygen species, ROS) from redox reactions over protective antioxidants. Of note, central nervous system tissue is particularly vulnerable to oxidative damage [22]. ROS are mostly generated by mitochondria, which play a key role in meeting cellular energy demands [23]. Importantly, decreases in mitochondrial numbers as well as changes in mitochondria morphology and function have been reported in schizophrenia [6] and BD [24]. In addition, mitochondrial DNA polymorphisms have been associated to increase familial risk for schizophrenia [25]. Finally, antioxidant defense systems appear to be compromised in schizophrenia [26]. In this line, aberrant peripheral markers for OS have been demonstrated in schizophrenia, BD [27], and MDD [28]. Multiple risk factors (obstetric complication, infections) and psychological stress are found to be associated with an increase in OS [29]. Oxidative damage to cell membranes, proteins, and DNA will impair cell function, signal transduction, and connectivity, which may account 
for the neuroprogressive course of these disorders [30]. Together, genetics and environmental factors contribute to OS in psychotic disorders through multiple pathways.

\section{Accelerated Aging}

The aforementioned immune system abnormalities as well as markers of OS have been associated with age in schizophrenia [20] and BD [27]. In fact, findings suggest an aggravation of immune-induced and oxidative damage with increasing age, significantly more so than in healthy elderly controls. Reversely, the free-radical theory of aging assumes that aging (partially) occurs as a result of damage to cells and connective tissue caused by free radicals [23]. In this line, several aging-related physiological abnormalities can be seen in younger patients with schizophrenia and mood disorders, including a higher prevalence of metabolic and cardiovascular disease, a reduction in life expectancy of 10-20 years, a reduced telomere length, and brain volume reductions $[23,31]$. These findings form the basis of the so-called "aging hypothesis" for schizophrenia and mood disorders [23, 27, 32], also suggesting these disorders to be "whole-body disorders" rather than disorders restricted to the brain [33].

\section{Implications}

A complex interaction between genetic predisposition [22], lifestyle choices [34, 35], psychological and other stressors [36] trigger immune abnormalities towards a proinflammatory state and induce OS. These changes lead to progressive cellular and structural damage [11, 37], resulting in symptoms related to the underlying disorders. Figure 1 summarizes these complex interactions. This notion opens up many interesting research avenues. Longitudinal studies could investigate how immune and oxidative processes are related to the progressive nature of these illnesses. Their relationship with mood and psychotic symptoms, but also with cognitive symptoms, should be gauged further. Motor symptoms such as catatonia and psychomotor slowing are typical features of psychotic and mood disorders, but to what extent they result from OS and immune changes is far from clear. When we look at catatonia as a case example, interesting findings point towards a role of the immune system: autoimmune encephalitis is often associated with catatonic features; a higher prevalence of catatonia has been demonstrated in winter months; increases in monocytes can be seen in catatonic patients irresponsive to lorazepam; and fever is present in some catatonic patients [38]. A case report describes the onset of catatonia after interferon treatment [39]. Furthermore, a mouse model of catatonia has been linked to mild inflammation of frontal white matter [40]. All these findings suggest a possible role of the immune system in the pathogenesis of catatonia. State and trait characteristics of these neurobiological abnormalities are another venue for research that can be explored. Finally, the use of peripheral markers can lead to diagnostical tools, especially when considering these psychiatric disorders as whole-body disorders, and may even define inflammatory subtypes of psychotic and mood disorders.

\section{References}

1 Lynham AJ, Hubbard L, Tansey KE, Hamshere ML, Legge SE, Owen MJ, et al. Examining cognition across the bipolar/schizophrenia diagnostic spectrum. J Psychiatry Neurosci. 2018 Jul;43(4):245-53

2 Walther S, Mittal VA. Motor System Pathology in Psychosis. Curr Psychiatry Rep. 2017 Oct;19(12):97.

3 Arnone D, Cavanagh J, Gerber D, Lawrie SM, Ebmeier KP, McIntosh AM. Magnetic resonance imaging studies in bipolar disorder and schizophrenia: meta-analysis. Br J Psychiatry. 2009 Sep;195(3):194-201.

4 Kumar J, Iwabuchi S, Oowise S, Balain V, Palaniyappan L, Liddle PF. Shared whitematter dysconnectivity in schizophrenia and bipolar disorder with psychosis. Psychol Med. 2015 Mar;45(4):759-70.
5 Walther S, Stegmayer K, Federspiel A, Bohlhalter S, Wiest R, Viher PV. Aberrant Hyperconnectivity in the Motor System at Rest Is Linked to Motor Abnormalities in Schizophrenia Spectrum Disorders. Schizophr Bull. 2017 Sep;43(5):982-92.

6 Rajasekaran A, Venkatasubramanian G, Berk M, Debnath M. Mitochondrial dysfunction in schizophrenia: pathways, mechanisms and implications. Neurosci Biobehav Rev. 2015 Jan;48:10-21.

7 Ottoy J, De Picker L, Verhaeghe J, Deleye S, Wyffels L, Kosten L, et al. 18F-PBR111 PET Imaging in Healthy Controls and Schizophrenia: Test-Retest Reproducibility and Quantification of Neuroinflammation. J Nucl Med. 2018 Aug;59(8):1267-74.
8 van den Ameele S, van Diermen L, Staels W, Coppens V, Dumont G, Sabbe B, et al. The effect of mood-stabilizing drugs on cytokine levels in bipolar disorder: A systematic review. J Affect Disord. 2016 Oct;203:36473.

9 van den Ameele S, Coppens V, Schuermans J, De Boer P, Timmers M, Fransen E, et al. Neurotrophic and inflammatory markers in bipolar disorder: A prospective study. Psychoneuroendocrinology. 2017 Oct;84:143-50.

10 van der Doef TF, Doorduin J, van Berckel BNM, Cervenka S. Assessing brain immune activation in psychiatric disorders: clinical and preclinical PET imaging studies of the 18$\mathrm{kDa}$ translocator protein. Clin Transl Imaging. 2015;3(6):449-60.
Are Mood and Psychotic Disorders Driven by Immune Dysregulations and OS?
Neuropsychobiology 2020;79:251-254 DOI: $10.1159 / 000496622$ 
11 De Picker LJ, Morrens M, Chance SA, Boche D. Microglia and Brain Plasticity in Acute Psychosis and Schizophrenia Illness Course: A Meta-Review. Front Psychiatry. 2017 Nov; 8:238.

12 Erhardt S, Schwieler L, Imbeault S, Engberg G. The kynurenine pathway in schizophrenia and bipolar disorder. Neuropharmacology. 2017 Jan;112 Pt B:297-306.

13 Sekar A, Bialas AR, de Rivera H, Davis A, Hammond TR, Kamitaki N, et al.; Schizophrenia Working Group of the Psychiatric Genomics Consortium. Schizophrenia risk from complex variation of complement component 4. Nature. 2016 Feb;530(7589):17783.

14 Condray R, Dougherty GG Jr, Keshavan MS, Reddy RD, Haas GL, Montrose DM, et al. 3-Hydroxykynurenine and clinical symptoms in first-episode neuroleptic-naive patients with schizophrenia. Int J Neuropsychopharmacol. 2011 Jul;14(6):756-67.

15 Goldsmith DR, Rapaport MH, Miller BJ. A meta-analysis of blood cytokine network alterations in psychiatric patients: comparisons between schizophrenia, bipolar disorder and depression. Mol Psychiatry. 2016 Dec;21(12): 1696-709.

16 Hafizi S, Guma E, Koppel A, Da Silva T, Kiang $\mathrm{M}$, Houle $\mathrm{S}$, et al. TSPO expression and brain structure in the psychosis spectrum. Brain Behav Immun. 2018 Nov;74:79-85.

17 Krogh J, Benros ME, Jørgensen MB, Vesterager L, Elfving B, Nordentoft $\mathrm{M}$. The association between depressive symptoms, cognitive function, and inflammation in major depression. Brain Behav Immun. 2014 Jan;35: 70-6.

18 Wilson KE, Demyanovich H, Rubin LH, Wehring HJ, Kilday C, Kelly DL. Relationship of Interferon- $\gamma$ to Cognitive Function in Midlife Women with Schizophrenia. Psychiatr Q. 2018 Dec;89(4):937-46.

19 Coughlin JM, Wang Y, Ambinder EB, Ward RE, Minn I, Vranesic M, et al. In vivo markers of inflammatory response in recent-onset schizophrenia: a combined study using [(11) C]DPA-713 PET and analysis of CSF and plasma. Transl Psychiatry. 2016 Apr;6(4): e777.
20 De Picker L, Ottoy J, Verhaeghe J, Deleye S, Wyffels L, Fransen E, et al. State-associated changes in longitudinal [18F]-PBR111 TSPO PET imaging of psychosis patients: evidence for the accelerated ageing hypothesis? Brain Behav Immun. 2019 Mar;77:46-54.

21 Notter T, Coughlin JM, Gschwind T, WeberStadlbauer U, Wang Y, Kassiou M, et al. Translational evaluation of translocator protein as a marker of neuroinflammation in schizophrenia. Mol Psychiatry. 2018 Feb; 23(2):323-34

22 Balmus IM, Ciobica A, Antioch I, Dobrin R, Timofte D. Oxidative Stress Implications in the Affective Disorders: Main Biomarkers, Animal Models Relevance, Genetic Perspectives, and Antioxidant Approaches. Oxid Med Cell Longev. 2016;2016:3975101.

23 Okusaga OO. Accelerated aging in schizophrenia patients: the potential role of oxidative stress. Aging Dis. 2013 Dec;5(4):256-62.

24 Valvassori SS, Bavaresco DV, Feier G, Cechinel-Recco K, Steckert AV, Varela RB, et al. Increased oxidative stress in the mitochondria isolated from lymphocytes of bipolar disorder patients during depressive episodes. Psychiatry Res. 2018 Jun;264:192-201.

25 Ichikawa T, Arai M, Miyashita M, Arai M, Obata N, Nohara I, et al. Schizophrenia: maternal inheritance and heteroplasmy of mtDNA mutations. Mol Genet Metab. 2012 Jan;105(1):103-9.

26 Singh OP, Chakraborty I, Dasgupta A, Datta S. A comparative study of oxidative stress and interrelationship of important antioxidants in haloperidol and olanzapine treated patients suffering from schizophrenia. Indian J Psychiatry. 2008 Jul;50(3):171-6.

27 van den Ameele S, Fuchs D, Coppens V, de Boer P, Timmers M, Sabbe B, et al. Markers of Inflammation and Monoamine Metabolism Indicate Accelerated Aging in Bipolar Disorder. Front Psychiatry. 2018 Jun;9:250.

28 Jiménez-Fernández S, Gurpegui M, DíazAtienza F, Pérez-Costillas L, Gerstenberg M, Correll CU. Oxidative stress and antioxidant parameters in patients with major depressive disorder compared to healthy controls before and after antidepressant treatment: results from a meta-analysis. J Clin Psychiatry. 2015 Dec;76(12):1658-67.
29 Brown AS. The environment and susceptibility to schizophrenia. Prog Neurobiol. 2011 Jan;93(1):23-58.

30 Davis J, Moylan S, Harvey BH, Maes M, Berk M. Neuroprogression in schizophrenia: pathways underpinning clinical staging and therapeutic corollaries. Aust N Z J Psychiatry. 2014 Jun;48(6):512-29.

31 Nguyen TT, Eyler LT, Jeste DV. Systemic Biomarkers of Accelerated Aging in Schizophrenia: A Critical Review and Future Directions. Schizophr Bull. 2018 Feb;44(2):398-408.

32 Kirkpatrick B, Messias E, Harvey PD, Fernandez-Egea E, Bowie CR. Is schizophrenia a syndrome of accelerated aging? Schizophr Bull. 2008 Nov;34(6):1024-32.

33 Shivakumar V, Kalmady SV, Venkatasubramanian G, Ravi V, Gangadhar BN. Do schizophrenia patients age early? Asian J Psychiatr. 2014 Aug; 10:3-9.

34 Rudzki L, Szulc A. "Immune Gate" of Psychopathology-The Role of Gut Derived Immune Activation in Major Psychiatric Disorders. Front Psychiatry. 2018 May;9:205.

35 Delaney S, Hornig M. Environmental Exposures and Neuropsychiatric Disorders: What Role Does the Gut-Immune-Brain Axis Play? Curr Environ Health Rep. 2018 Mar;5(1): 158-69.

36 Mondelli V, Vernon AC, Turkheimer F, Dazzan P, Pariante CM. Brain microglia in psychiatric disorders. Lancet Psychiatry. 2017 Jul;4(7):563-72.

37 Bakunina N, Pariante CM, Zunszain PA. Immune mechanisms linked to depression via oxidative stress and neuroprogression. Immunology. 2015 Mar;144(3):365-73.

38 Rao NP, Mutalik NR, Kasal V, Venkatasubramanian G, Behere RV, Varambally S, et al. Monocyte abnormality in catatonia: revisiting the immune theory of catatonia. J ECT. 2011 Sep;27(3):e53-4.

39 Quinn D, Kuchler E, Deming P, Arora S. Catatonia associated with pegylated interferon- $\alpha 2 b$ and ribavirin for hepatitis C. Psychosomatics. 2012 Jul-Aug;53(4):400-1.

40 Janova H, Arinrad S, Balmuth E, Mitjans M, Hertel J, Habes M, et al. Microglia ablation alleviates myelin-associated catatonic signs in mice. J Clin Invest. 2018 Feb;128(2):734-45. 